\title{
Facing the Climate Change in Agriculture: Genetic Modified Organisms, Organic Agriculture or Agro-Ecology?
}

ISSN: 2637-7659

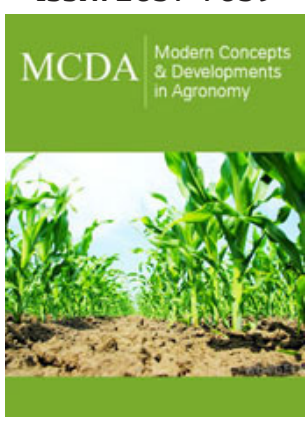

*Corresponding author: Y Beovides García, Doctor of Biological Sciences, Titular Researcher from Department of Biotechnology, Research Institute of Tropical Roots and Tuber Crops (INIVIT), Apdo 6, Santo Domingo, CP 53 000, Villa Clara, Cuba

Submission: 婹 August 14, 2019

Published: 制August 20, 2019

Volume 5 - Issue 1

How to cite this article: Y Beovides García. Facing the Climate Change in Agriculture: Genetic Modified Organisms, Organic Agriculture or Agro-Ecology?. Mod Concep Dev Agrono.5(1). MCDA.000602.2019. DOI: 10.31031/MCDA.2019.05.000602

Copyright@ Y Beovides García, This article is distributed under the terms of the Creative Commons Attribution 4.0 International License, which permits unrestricted use and redistribution provided that the original author and source are credited.

\author{
Y Beovides García* \\ Titular Researcher from Department of Biotechnology, Cuba
}

\section{Opinion}

The world faces a multidimensional crisis: economic, ecological and social. There are very complex problems to solve and for this, a multidisciplinary approach is necessary. A recent special report from the Intergovernmental Panel on Climate Change (IPCC) on climate change, desertification, land degradation, sustainable land management, food security, and greenhouse gas fluxes in terrestrial ecosystems provides an updated assessment of the current state of knowledge about climate change and related topics. The discoveries are highly worrisome, but the risk perception is still generally low. Climate change is mainly caused by natural factors and anthropogenic factors: change in solar radiation, greenhouse gases, deforestation, changes in land and water use pattern, energy uses, etc. The enormous emissions of greenhouse gases in the environment as a result of industrialization and urbanization phenomena in the course of growing human civilization is considered to be the main causal factors accelerating climate change.

In my opinion, weak linkages among institutions and countries have resulted in fragmentation, uncoordinated efforts and affect the ability to integrate the results to achieve a more comprehensive response to challenges of climate change. Agricultural productivity and hence, food and nutrition security will be significantly impacted by climate change (it is being affected nowadays), but at the same time, global agricultural production also contributes to climate change. However, the contribution and responsibilities of countries and types of agriculture are different. On the other hand, we can't obviate the agriculture is one of the few global industries, which is mostly supported by family production around the world, and these small farms often support some of the world's most vulnerable populations. Adaptation and mitigation strategies to reduce the impact of climate change on agricultural productivity and food and nutrition security goals are indispensable. Science-based policies are critical for the implementation of adaptation strategies which also take climate variability into consideration. In this sense, various technologies or practices can be developed in current farming operations to reduce the impact of climate change e.g. protected agriculture, water harvesting, drought tolerant crops. Like in other important topics, the defenders of each possible alternative believe that they have the 'magic' solution; however, it is not like that and maybe, the best option is to consider a scientific holistic point of view. I consider a privilege to write my opinion and some ideas about the controversial contribution of genetically modified organism (GMO), the organic agriculture or agro-ecology to face the climate change. I think that if they are used properly, they can contribute positively to increase the production and the sustainability of agricultural systems, but it is not enough at the present time. Plant biotechnology, for example supports innovative advances in agriculture and industry, offering new prospects to promote the integration and dissemination of improved crops and their derivatives from developing countries into local markets and the global economy.

Through tissue culture is possible to obtain planting material with high quality of major crops in order to enhance both, national food security and export diversification. We can reproduce elite varieties with high yields and other expected characteristics, too. We can increase areas and yield in several crops with GMO when all other growth measures are also well implemented; GM crops can contribute to poverty reduction and food security in 
developing countries. Nevertheless, a high production is not enough: what about the rest of the food chain? There is sufficient food, but they are distributed incorrectly. Rules and policies of distribution and consumption must be checked and changed. The strategy of GMO is good, but there are some failures of genetically engineered crops. Even if we ignore the environmental and health concerns for GM crops, there are other topics which give rise to concern. One is the idea that this kind of crops are the only way to feed the world: that's not true. The other is the control of the world's food supply by just a few agribusinesses. GMO can help to food security, but we need more efficient regulatory and technology delivery systems. Due to the unsustainable management of production systems during many decades, a current problem is that most of the world's soil is in a degraded and often deteriorating state due to erosion, compaction, acidification, salinization and the chemical pollution.

However, millions of people are living on degraded agricultural lands. The spread of inappropriate crop-production practices makes the defenders of the organic agriculture, believe that organic farming is the solution. On the other hand, some countries realize that new technologies are contributing to replace traditional lifestyles and the loss of traditional ecological knowledge. I think that the organic agriculture integrates cultural, biological and mechanical practices which promote biodiversity. When it is applied properly, organic farming is able to maintain the ecosystem balance. But unfortunately, organic farming requires much more work to produce goods to be ready for sale; it usually costs more to be competitive with this kind of agriculture, and it becomes difficult to manage large tracts of land in production, so that its productions are still with good quality, but with a limited and specific market coverage, among other disadvantages. However, its principles are essential to strengthen the family agriculture and create inclusive agricultural systems. Urban agriculture is a nice example; it can provide fresh food, job opportunities and other benefits for communities. Some researchers consider that because of the climatic change, the agro-ecology is one of the best alternatives that we have to face the challenge. They see agrobiodiversity at the center of human development and economic prosperity. This alternative considers the development of different crops and varieties, and the use of genetically heterogeneous crops, it can be adopted as a mechanism to reduce risks and increase overall production stability. I agree with the idea that access to diversity, provides farmers with a range of options to deal with climate variability; this aspect needs to be given more importance. Crop diversity offers a cost-effective way to increase productivity, adaptation to climatic and manage crop pests and diseases; it also provides diverse, healthy and nutritious foods. One of the most effective ways for agriculture to mitigate the climate change could be to increase its resilience, and genetic diversity is the basis for breeding new crop varieties to face challenges for food security. For that reason, I think that agro-ecology seems as an important way to face climate change because this alternative includes all the best from the traditional methods, technologies and process that work in strict respect to the environment. It combines principles of organic agriculture and technology in order to protect the soil and water, to use integral production systems able to produce more and with much more quality, and it takes into account the eco-systemic services.

In a few words, we should understand that to reduce climate risks in agriculture, different alternatives must be applied. The world should move to a climatic smart agriculture and it is necessary to establish a leadership in good agricultural practices and mechanisms to share positive experiences and implement them. I believe that the bond among climatic change, the use of the land and the agricultural practices, as well as their consequences in the biodiversity should occupy a significant space in the national discussions. We need to stop the loss and degradation of forest and aquatic ecosystems. We need to stop the ecosystems fragmentation and recognize the importance of diversity and its role in food security. To eradicate the hunger, a change of paradigm is required towards a fully sustainable agricultural model that protects its natural resources, generate equal socioeconomic development and allow to adapt to the global change and mitigate its effects. Then, all the alternatives that promote a sustainable, efficient and productive agriculture are useful.

The uncertainties are big and the vulnerabilities exist. However, the new intervention capacities in nature and over the own man, demands to the science new and meaningful ethical problems related to its aims, reaches and procedures. Huge uncertainties on the way to climate change will impact agricultural and food systems directly and indirectly. Building resilience is essential to being prepared for future changes, because it can bring about enormous direct benefits on food security and hunger eradication. An appropriate action is needed, especially to avoid accumulative and long-term effects of climate change. It's necessary and possible a whole change, maybe it will not be easy, but the solutions are in our hands.

\section{Acknowledgement}

I would like to thanks Ms. Geisy Díaz Roche for her contribution to the revision and for comments that greatly improved the original manuscript.

\section{Conflict of Interest}

The author declares that he has no conflict of interest.

For possible submissions Click below: 